\section{Fatores de risco para a cárie dental em crianças na primeira infância, Salvador - BA}

\section{Risk factors for dental caries in early childhood in Salvador, in the Brazilian State of Bahia}

Maria Cristina Cangussu1

Maria Beatriz Barreto de Sousa Cabral 2

Eduardo Luiz Andrade Mota 3

Maria Isabel Pereira Vianna 4

1-4 Universidade Federal da Bahia. Rua Araújo Pinho, 62. 6º andar. Canela. Salvador, BA, Brasil. CEP 41110-150.

E-mail: cangussu@ufba.br

\section{Resumo}

Objetivos: identificar fatores associados a incidência de cárie na primeira infância.

Métodos: realizou-se estudo de coorte prospectivo (14 meses) com 495 crianças de 4 a 30 meses de creches públicas, privadas e filantrópicas em Salvador-BA.

Resultados: a média de dentes cariados foi de $0,18(D P=0,75)$ no início do estudo e 0,55 (DP=1,40) ao final. A incidência em crianças livres de cárie foi $18,5 \%$ e no grupo total 22,6\%. Na análise de regressão logística, consideraram-se três modelos. Com todas as crianças $(N=495)$, prevaleceu: experiência prévia de cárie $(O R=6,8 ; I C 95 \%=3,0-15,1)$, frequentar creche pública $(O R=2,9 ;$ IC95\%= 1,65,3), idade maior 24 meses. No segundo, de creches públicas $(N=329)$ : idade, aleitamento durante o sono $(O R=1,9 ; \quad I C 95 \%=1,1-3,2), \quad$ mancha branca $(O R=3,5 ; I C 95 \%=1,1-11,3)$, casa sem revestimento $(O R=2,3 ; I C 95 \%=1,2-4,1)$ e experiência prévia de cárie $(O R=3,9 ; I C 95 \%=1,5-10,6)$. No terceiro, com crianças sem cárie no início $(N=495)$ : frequentar creche pública, idade, cor da pele negral parda $(O R=5,5 ;$ IC95\%= 1,3-23,8) e aleitamento durante $o$ sono após um ano $(O R=1,7 ; \mathrm{IC} 95 \%=1,0-2,8)$.

Conclusões: a vulnerabilidade social foi um forte fator de risco à cárie em crianças menores de dois anos e é necessária melhoria das condições de vida e ações de promoção de saúde bucal para redução da morbidade.

Palavras-chave Cárie dental, Incidência, Fatores de risco, Condições socioeconômicas 


\section{Introdução}

A importância da cárie como grave e persistente problema de saúde coletiva está representada pela ampla distribuição populacional da doença e o comprometimento de diferentes grupos de acordo com aspectos socioeconômicos e demográficos. 1-3

No Brasil, apesar do acentuado declínio na prevalência de cárie na população escolar, ${ }^{4}$ o problema ainda se manifesta de forma crítica em outros grupos etários, a exemplo das crianças com idade abaixo de 36 meses. Por exemplo, os levantamentos nacionais publicados em 2004 e 2010, aos cinco anos de idade, apresentaram respectivamente o ceo-d (média de dentes cariados perdidos e obturados na dentição decídua) de 2,9 e 2,6 e apenas $40,6 \%$ e $46,6 \%$ de crianças livres de cárie, com piores condições para a Região Nordeste.5,6

A cárie precoce na infância se constitui em importante problema de saúde em muitos países 7-11 e também no Brasil.1,12-17 A presença desta doença em crianças de pouca idade pode adquirir características destrutivas específicas, tendo como consequências indesejáveis, dentre outras, a ocorrência de dor e infecção. Estas, por sua vez, podem determinar um padrão inadequado de alimentação, comprometendo o desenvolvimento físico da criança. 18,19 Ressalta-se também a questão estética, que pode afetar o seu convívio social, provocando isolamento e timidez.

Os primeiros anos de vida são considerados os de maior risco para o desenvolvimento de cárie dental na dentição decídua. ${ }^{11}$ Ademais, condições de saúde gerais e bucais sofrem o impacto de fatores presentes desde o início da vida, a exemplo de níveis mais baixos de escolaridade materna, do baixo peso ao nascer e da má-nutrição. Esses fenômenos parecem incrementar o risco de cárie dental e são mais prevalentes em áreas de maior privação.3,20-22 É também sugerido que riscos sociais e biológicos, acumulados desde a infância, ${ }^{18}$ têm consequências para a condição de saúde na idade adulta. Além disto, crianças de pouca idade, com cárie na dentição decídua, têm maior probabilidade de desenvolver esta doença em sua dentição permanente. ${ }^{23}$

As principais dificuldades para a estruturação da atenção à saúde bucal do referido grupo etário no Brasil são: o modelo hegemônico de atenção odontológica, eminentemente cirúrgico-restaurador e voltado para o escolar; a pouca importância atribuída à primeira dentição e a dificuldade no manejo de crianças de pouca idade, incluindo ainda a dieta e o consumo de açúcar,2,24 hábitos de aleitamento19,24 e higiene oral.10,24 Estes aspectos, a ausência de estruturação de serviços multidisciplinares voltados para a primeira infância no estado e no município incluindo a odontologia e o limitado conhecimento sobre os fatores responsáveis pelo início e progressão da cárie precoce da infância e suas relações com os comportamentos de risco, normas culturais, crenças e atitudes em relação à saúde $21-23$ constituem enormes desafios. 25

Assume-se que o método epidemiológico quando utilizado em estudos cujo interesse é evidenciar fatores de risco sócio-ambientais envolvidos em diferentes processos saúde-doença, a exemplo da cárie dentária, contribui para ampliar a compreensão do papel da determinação social dos mesmos, de modo específico na infância, ${ }^{26}$ além de subsidiar a tomada de decisão para a implementação de políticas de saúde. Além disso, as iniquidades em saúde estão fortemente presentes na realidade brasileira, incluída a distribuição de cárie dental.

Considerando a escassez de estudos longitudinais sobre a cárie precoce na infância num contexto de vulnerabilidade social, este estudo tem o objetivo de analisar a associação entre fatores referentes às condições socioeconômicas e demográficas, comportamentais e de saúde bucal e a incidência da cárie dentária nos primeiros anos de vida em uma população infantil de creches públicas, privadas e filantrópicas em Salvador, Bahia.

\section{Métodos}

Um estudo prospectivo de coorte dinâmica foi realizado envolvendo crianças de quatro a 30 meses matriculadas em creches públicas, privadas $\mathrm{e}$ filantrópicas localizadas em dois distritos de saúde do município de Salvador-Bahia, Nordeste do Brasil. O Barra-Rio Vermelho está localizado no sul da cidade, envolvendo bairros de diferentes perfis socioeconômicos. Nele foram identificadas vinte creches (cinco privadas, oito públicas e sete filantrópicas). O distrito Cabula Beiru está localizado no norte da cidade, com uma predominância de habitações populares e muitas áreas de ocupação irregular, com sérios problemas de infra-estrutura urbana. Neste distrito foram identificadas quatro creches públicas e sete creches filantrópicas.

O estudo buscou envolver a totalidade das crianças matriculadas nas creches identificadas nos dois distritos. Todas as creches foram incluídas no estudo. Após o contato prévio com a creche, foram enviadas cartas a todos os responsáveis pelas crianças, explicando os objetivos da pesquisa, bem como o termo de consentimento informado a ser assinado. Do total de 640 crianças matriculadas, foi obtido retorno positivo de $86,9 \%$ dos participantes. 
Este foi considerado o critério de inclusão no estudo. As crianças foram acompanhadas durante catorze meses (entre outubro de 2002 e dezembro de 2003), sendo examinadas, por um único investigador, no início da coorte, no sexto e no décimo quarto meses de acompanhamento.

A coleta de dados, realizada antes do exame, envolveu a realização de entrevista padronizada com a mãe ou cuidador e exame clínico da criança. $\mathrm{Na}$ entrevista as variáveis consideradas foram: idade ( $\geq 24$ meses/<24 meses); sexo (masculino / feminino); cor da pele (branco / preto-pardo); distrito de residência (Barra-Rio Vermelho / Cabula- Beiru); tipo de creche (pública / privada/filantrópica); escolaridade da mãe e do pai (até ensino médio incompleto / ensino médio completo ou superior); ocupação da mãe e do pai (nível médio-superior / baixa qualificação / desempregado); idade materna ( $\geq 20$ anos / $<20$ anos); renda familiar per capita (em salários mínimos- $<0,38 \mathrm{SM}$ e $\geq 0,38 \mathrm{SM}$ ); estado civil da mãe (presença / ausência de companheiro); número de irmãos (nenhum-um irmão / mais de um irmão); número de pessoas por cômodo (até duas pessoas / mais de duas pessoas); água encanada na residência (presente / ausente); condição da moradia (presença/ausência de revestimento); tipo de aleitamento (misto e natural / artificial); tempo de aleitamento artificial ( $\geq 24$ meses $/<24$ meses); uso de mamadeira à noite ( $\geq 24$ meses $/<24$ meses); aleitamento durante o sono ( $\geq 12$ meses / $<12$ meses), uso de açúcar (antes 6 meses / após 6 meses); higiene bucal (antes de 12 meses / após 12 meses); frequência de escovação (duas vezes por dia ou mais/ uma vez por dia ou raramente/ nunca).

O exame clínico foi realizado por uma equipe composta por um examinador calibrado durante 12 horas, divididas em 3 turnos, e dois anotadores. Utilizou-se um instrumento incluindo: número de dentes presentes, presença de hipoplasia do esmalte, presença de placa visível (PV), ${ }^{25}$ cárie ${ }^{5,6}$ e presença de cárie em estágio inicial - Mancha Branca Ativa (MBA), ${ }^{7}$ quando a superfície do esmalte apresenta cor branca opaca, aparência irregular. O índice Kappa para a concordância intra-examinador variou 0,93-0,98 para cada situação observada após a reprodução de $10 \%$ dos exames pelo menos 10 dias após o primeiro exame.

As crianças foram examinadas no ambiente da creche, com o examinador utilizando luvas descartáveis, espátulas de madeira, sonda periodontal, recomendada pela Organização Mundial da Saúde para o exame da cárie dentária7 e uma lanterna de luz branca. Os critérios diagnósticos considerados foram: presença de placa bacteriana - acúmulo de depósito macio, visível, solto ou preso nas superfícies vestibulares dos dentes incisivos superiores decíduos, identificados durante a inspeção visual. Enfatiza-se que esta condição foi avaliada somente na segunda oportunidade do exame ${ }^{25}$; MBA de cárie; lesões de cárie ativas evidência clínica de atividade de cárie; cárie inativa - aspecto crônico de cavitação e coloração escura; dente obturado - presença de material restaurador definitivo; extração indicada - extensa destruição coronária e consequente envolvimento pulpar. ${ }^{9}$ A criança foi considerada com cárie quando havia uma ou mais cavidade de aspecto agudo ou crônico ou com extração indicada.5,6 As lesões incipientes MBA, uma vez que têm um caráter reversível, não foram consideradas como unidades/superfícies cariadas no índice ceo-d.

Para a etapa analítica do estudo foi considerada, como variável dependente, a ocorrência de cárie após o primeiro exame, categorizada como ausência ou presença de novas lesões cavitadas de aspecto agudo ou crônico.5,6 As variáveis independentes socioeconômicas, demográficas e comportamentais, foram categorizadas conforme descrito anteriormente.

As medidas de ocorrência utilizadas foram a densidade de incidência, razão entre número de indivíduos que apresentaram novas lesões de cárie por 100 crianças-dia de acompanhamento e a incidência acumulada, obtida pela razão do número de crianças que desenvolveram cárie durante o período de acompanhamento dividido pelo total de crianças sob risco. $\mathrm{Na}$ análise univariada, realizada com dados categorizados, adotou-se, como medida de associação o Risco Relativo (RR) com o respectivo Intervalo de Confiança a 95\% (IC) pelo método Taylor Series 7 e o Teste qui-quadrado de Mantel-Haenszel, considerando-se estatisticamente significantes os valores de $p<0,05$. Foram selecionadas as variáveis candidatas ao modelo de análise multivariado, escolhendo-se aquelas que apresentaram associação com a variável resposta ao nível de significância estatística de 5,0\% e mantendo-se no modelo as variáveis que apresentaram significância de até $10 \%$.

Considerando o período de tempo e a presença de incidência de cárie, seguiu-se a análise multivariada utilizando a regressão logística não condicional. Ao modelo inicial saturado, com todas as variáveis selecionadas, foi-se retirando uma a uma, cujo valor de $p$ era superior ao pré-estabelecido, até o modelo final, onde permaneceram aquelas que se mantiveram com significância estatística ou que mais contribuíram para a explicação do efeito.

Durante o procedimento da análise multivariada 
para avaliar a associação entre possíveis fatores de risco e a ocorrência de cárie, foram definidos três modelagens: a) todas as crianças acompanhadas no período; b) todas as crianças acompanhadas no período, por tipo de creche e c) todas as crianças acompanhadas no período e que, no início do estudo, se encontravam livres da doença. A magnitude da associação entre incidência de cárie e seus potenciais determinantes, foi verificada pelo cálculo da $O d d s$ ratio (OR), cuja medida de precisão foi o intervalo de confiança a $95 \%$.

Os programas estatísticos utilizados foram o Stata, versão 7.0 e o Epi-Info versão 6.04.

O projeto foi aprovado pelo Comitê de Ética em Pesquisa do Instituto de Saúde Coletiva da Universidade Federal da Bahia paracer 23/ 2002.

\section{Resultados}

Do universo de 640 crianças matriculadas nas creches nos dois distritos sanitários selecionados para o estudo, $556(86,9 \%)$ crianças foram incluídas por obedeceram ao critério de inclusão, isto é, participar do primeiro exame. Destas, 495 crianças $(89,0 \%)$ com idade entre 4 e 30 meses foram acompanhadas, por 14 meses, sendo $214(43,2 \%)$ com idade entre 13 e 24 meses e 237 (47,9\%) do sexo feminino. A incidência acumulada de cárie, calculada para 112 indivíduos que apresentaram novas lesões, foi de $22,6 \%$ e a taxa de incidência foi de 2,6 casos por 100 crianças-mês. Observou-se que $91,9 \%$ das crianças estavam livres de cárie no início do acompanhamento. Destas, 81,5\% (371/455) permaneceram nessa condição. No grupo de crianças livres de cárie no início do estudo, a taxa de incidência foi de $18,5 \%$. O índice ceo-d (médio) na população estudada variou de 0,18 (desvio padrão $=0,75$ ) no início do estudo a 0,55 (desvio padrão=1,40) no final do acompanhamento.

Foram evidenciadas maiores proporções de crianças com lesões cavitadas nos estratos de maior idade, de cor da pele preta ou parda, de menor renda média familiar per capita, quando os pais da criança apresentavam baixa escolaridade e ocupação com níveis menores de qualificação e naquelas com hábitos de aleitamento artificial, durante o sono e com maior uso de açúcar. Outras condições clínicas orais como presença de placa e presença de mancha branca ativa também foram importantes na incidência neste grupo (Tabela 1).

$O$ fato de a criança pertencer ao Distrito Sanitário com indicadores de condições de vida mais precários, de ter mais de um irmão e possuir condições de moradia insatisfatórias (com maior número de pessoas por cômodo, ausência de água encanada e falta de revestimento) foram fatores associados à cárie dental, em todas as 3 modelagens (Tabelas 2, 3 e 4).

Considerando as variáveis comportamentais e outras condições de risco, estiveram mais fortemente associadas ao evento, os fatores: aleitamento artificial prolongado ( $>24$ meses); uso mais frequente do açúcar na alimentação; presença de placa bacteriana visível; presença de lesões incipientes e experiência anterior de cárie. Foram fatores de risco associados à incidência de cárie as seguintes condições: aleitamento antes de dormir ( $>24$ meses $)(p=0,002)$, bem como do aleitamento durante o sono ( $>12$ meses) $(p=0,002)$, o início tardio da higiene oral (após 12 meses) $(p=0,056)$ e a presença de hipoplasia de esmalte $(p=0,067)$ (Tabela 1$)$.

Na regressão logística foram incluídas todas as variáveis analisadas, que apresentaram associação positiva com a ocorrência de cárie nas análises individuais e, após ajuste simultâneo das variáveis, encontraram-se os seguintes resultados: para o grupo total de crianças $(\mathrm{N}=495)$, prevaleceram no modelo final, a variável experiência anterior de cárie $(p<0,001)$; o tipo de creche $(p=0,00)$ e a idade da criança $>24$ meses $(p<0,001)$ (Tabela 2 ).

$\mathrm{Na}$ análise multivariada por tipo de creche, para as creches filantrópicas $(\mathrm{N}=102)$ contribuíram com associação positiva apenas as variáveis experiência anterior de cárie $(p<0,001)$ e o período em que a criança utilizou o aleitamento artificial $(p=0,05)$, embora esta última variável tenha apresentado parâmetros no limite da significância estatística. Considerando a creche pública $(\mathrm{N}=329)$, as variáveis que contribuíram para a explicação do evento, de forma estatisticamente significante, foram: a idade da criança $(p<0,001)$, o período em que fez uso do aleitamento durante o sono $(p=0,02)$, a presença de mancha branca ativa $(p=0,04)$, o fato de a casa onde reside não ser revestida $(p=0,01)$ e a experiência anterior de cárie $(p=0,01)$ (Tabela 3$)$.

Por fim, ao se considerar o grupo de crianças sem cárie no início do estudo $(\mathrm{N}=455)$, os fatores que contribuíram para a incidência da cárie e que apresentaram significância estatística foram: o tipo de creche $(p<0,001)$, a idade da criança $(p=0,001)$, a cor da pele $(p=0,021)$ e o período de aleitamento durante o sono $(p=0,033)$ (Tabela 4$)$. 
Fatores de risco socioeconômicos e demográficos, comportamentais e de condições de saúde bucal associados a incidência de cárie dentária em crianças menores de 30 meses entre 2002-2003, Salvador- BA, 2015 (N=495).

\begin{tabular}{|c|c|c|c|c|c|c|}
\hline \multirow[t]{3}{*}{ Fatores de risco } & \multirow{3}{*}{$\begin{array}{c}\text { Amostra } \\
(\mathrm{N}=495) \\
\%\end{array}$} & \multicolumn{2}{|c|}{$\begin{array}{l}\text { Incidência } \\
\text { de cárie }\end{array}$} & \multirow[t]{3}{*}{ RR1 } & \multirow[t]{3}{*}{ IC95\% 2} & \multirow[t]{3}{*}{$p^{3}$} \\
\hline & & \multicolumn{2}{|c|}{ Exposto Não exposto } & & & \\
\hline & & ceod $>0$ & ceod $=0$ & & & \\
\hline \multicolumn{7}{|l|}{ Socioeconômicos e demográficos } \\
\hline Idade $>24$ meses & 44,0 & 32,1 & 15,6 & 2,1 & $1,5-3,0$ & $<0,001$ \\
\hline Cor da pele preta/ parda & 87,1 & 25,3 & 4,7 & 5,4 & $1,8-16,5$ & 0,002 \\
\hline Pertencer ao distrito $\mathrm{B}$ & 38,4 & 28,4 & 19,0 & 1,5 & $1,1-2,1$ & 0,015 \\
\hline Frequentar creche pública & 66,5 & 27,4 & 13,2 & 2,1 & $1,4-3,2$ & 0,001 \\
\hline Escolaridade materna até $1^{\circ} \mathrm{Grau}(\mathrm{n}=490)$ & 48,2 & 29,7 & 16,5 & 1,8 & $1,3-2,5$ & 0,001 \\
\hline Escolaridade paterna até $1^{\circ} \mathrm{Grau}(\mathrm{n}=451)$ & 54,5 & 27,6 & 14,1 & 2,0 & $1,3-2,9$ & 0,001 \\
\hline Renda per capita <0,38 SM4 $(n=469)$ & 61,8 & 27,9 & 16,2 & 1,7 & $1,2-2,5$ & 0,004 \\
\hline Ocupação do pai Grupo B5 $(n=434)$ & 77,2 & 27,2 & 9,1 & 3,0 & $1,6-5,7$ & $<0,001$ \\
\hline Ocupação da mãe Grupo B5 $(n=492)$ & 83,3 & 26,3 & 4,9 & 5,4 & $2,1-14,2$ & $<0,001$ \\
\hline Ausência de companheiro & 36,8 & 27,5 & 19,8 & 1,4 & $1,0-1,9$ & 0,049 \\
\hline Número de irmãos $\geq 2$ & 33,5 & 28,3 & 19,8 & 1,4 & $1,0-2,0$ & 0,032 \\
\hline Número de pessoas/ cômodo>3 & 45,8 & 28,6 & 17,5 & 1,6 & $1,2-2,3$ & 0,003 \\
\hline Ausência de água encanada & 5,5 & 37,0 & 21,8 & 1,7 & $1,0-2,9$ & 0,066 \\
\hline Casa sem revestimento & 19,6 & 33,0 & 20,1 & 1,6 & $1,2-2,3$ & 0,007 \\
\hline \multicolumn{7}{|l|}{ Comportamentais } \\
\hline Aleitamento artificial $\geq 2$ anos & 13,9 & 39,1 & 19,9 & 2,0 & $1,4-2,8$ & $<0,001$ \\
\hline Aleitamento antes de dormir $\geq 2$ anos & 34,3 & 32,3 & 17,5 & 1,8 & $1,3-2,5$ & 0,002 \\
\hline Aleitamento durante $o$ sono $\geq 1$ ano & 46,0 & 28,9 & 17,2 & 1,7 & $1,2-2,3$ & 0,002 \\
\hline Uso de açúcar & 87,9 & 24,8 & 6,7 & 3,7 & $1,4-9,7$ & 0,002 \\
\hline Inicio da higiene $\geq 1$ ano & 19,6 & 29,9 & 20,8 & 1,4 & $1,0-2,1$ & 0,056 \\
\hline \multicolumn{7}{|l|}{ Condições de saúde bucal } \\
\hline Presença de placa bacteriana visível & 79,2 & 27,0 & 5,9 & 4,6 & $2,1-10,3$ & $<0,001$ \\
\hline Presença de mancha branca ativa & 5,5 & 51,8 & 20,9 & 2,5 & $1,7-3,7$ & 0,001 \\
\hline Presença de hipoplasia de esmalte & 6,9 & 35,3 & 21,7 & 1,6 & $1,0-2,7$ & 0,067 \\
\hline Experiência prévia de cárie & 8,1 & 70 & 18,5 & 3,8 & $2,9-5,0$ & $<0,001$ \\
\hline
\end{tabular}

1 Risco Relativo calculado para cada fator de risco como razão de frequência de expostos/ não expostos;

2 Intervalo de Confiança a 95\%;

3 Teste qui-quadrado de Mantel Haensel;

4 Salário Mínimo = R $\$ 240,00$;

5 De acordo com a Classificação Brasileira de Ocupação estabeleceram-se 2 grupos: A- profissionais de nível superior ou técnico qualificados e B- desempregados ou trabalhadores não qualificados. 
Tabela 2

Modelo final dos fatores de risco associados à ocorrência de cárie dental da amostra de crianças menores de 30 meses. Salvador-BA, 2002-2003.

\begin{tabular}{lccc}
\hline Fator de risco & OR ajustado & IC95\% & $\boldsymbol{p}^{*}$ \\
\hline Frequentar creche pública & 2,92 & $1,61-5,31$ & 0,00 \\
Idade >24 meses & 2,44 & $1,52-3,93$ & $<, 001$ \\
Cor da pele preta/parda & 2,91 & $0,84-10,81$ & 0,10 \\
Aleitamento durante o sono $\geq 1$ ano & 1,61 & $0,92-2,53$ & 0,07 \\
Presença de mancha branca ativa & 2,02 & $0,82-5,31$ & 0,15 \\
Presença de placa bacteriana & 2,53 & $0,91-6,53$ & 0,06 \\
Experiência anterior de cárie & 6,81 & $3,02-15,11$ & $<0,001$ \\
\hline
\end{tabular}

Método empregado: backward; Teste de máxima verossimilhança $p<0,0001 ; \mathrm{N}=495$.

*Significância estatística determinada pelo "Wald Test".

Tabela 3

Modelo final dos fatores de risco por tipo de creche associados à ocorrência de cárie dental da amostra de crianças menores de 30 meses. Salvador-BA, 2002-2003.

\begin{tabular}{lccc}
\hline Fator de risco & OR ajustado & IC95\% & $\boldsymbol{p}^{*}$ \\
\hline Creche filantrópica $(\mathrm{N}=102)$ & & & 0,05 \\
$\quad$ Aleitamento artificial $>2$ anos & 3,33 & $1,01-11,23$ & $<, 001$ \\
Experiência anterior de cárie & 13,71 & $3,92-48,84$ & $<0,001$ \\
& & & 0,02 \\
Creche pública (N=329) & & $1,53-4,51$ & 0,04 \\
Idade $>24$ meses & 2,62 & $1,13-3,24$ & $1,13-11,32$ \\
Aleitamento durante o sono $\geq 1$ ano & 1,92 & $1,24-4,16$ & 0,01 \\
Presença de mancha branca ativa & 3,51 & $1,51-10,63$ & 0,01 \\
Casa sem revestimento & 2,37 & 3,91 &
\end{tabular}

Método empregado: backward; Teste de máxima verossimilhança $p<0,0001 ; \mathrm{N}=495$.

*Significância estatística determinada pelo "Wald Test".

Tabela 4

Modelo final dos fatores de risco em creches públicas associados à ocorrência de cárie dental da amostra de crianças menores de 30 meses. Salvador-BA, 2002-2003.

\begin{tabular}{lccc}
\hline Fator de risco & OR ${ }_{\text {ajustado }}$ & IC95\% & $\boldsymbol{p}^{*}$ \\
\hline Frequentar creche pública & 3,61 & $1,82-7,31$ & $<0,001$ \\
Idade $>24$ meses & 2,42 & $1,53-4,02$ & 0,001 \\
Cor da pele preta/ parda & 5,57 & $1,34-23,8$ & 0,021 \\
Aleitamento durante o sono $\geq 1$ ano & 1,74 & $1,08-2,81$ & 0,033 \\
\hline
\end{tabular}

Método empregado: backward; Teste de máxima verossimilhança $p<0,0001 ; \mathrm{N}=455$.

* Significância estatística determinada pelo "Wald Test". 


\section{Discussão}

No presente estudo, observou-se, em um período relativamente curto de acompanhamento, uma elevada incidência acumulada de cárie, assim como da densidade de incidência (2,6 casos/ 100 crianças mês). O ceo-d teve o seu valor inicial triplicado, ao término de um ano. Contudo, convém enfatizar que, apesar dos valores de incidência encontrados, houve um percentual elevado de crianças livres de cárie ao fim do seguimento $(81,5 \%)$.

Ocorreu concentração de casos de cárie em uma parcela relativamente pequena da população estudada, o que sugere a existência de um grupo de polarização que manifesta a doença de forma mais intensa e severa, caracterizando-se por apresentar um maior risco de desenvolver a doença. O fenômeno da polarização ou dos grupos de alta atividade de doença tem sido documentado em vários países industrializados 19,24,25,27 e em desenvolvimento. $1,2,10,11$

Dentre os aspectos estudados, destacam-se aqueles que contribuíram, de forma mais preponderante, para a ocorrência do evento em questão, nas diferentes análises multivariadas realizadas. Sendo assim, a variável tipo de creche se manteve em todos eles e foi escolhida para se avaliar os demais fatores de risco, de acordo com a sua natureza - privada ou filantrópica e pública. Resultado similar foi observado por Melo et al. 1 em Recife, Pernambuco em crianças de 18 a 36 meses, que apontou maior risco de cárie em crianças matriculadas de creches públicas. Tal variável pode ser considerada proxy de piores condições socioeconômicas, por discriminar, de forma bastante definida, esse perfil, resultado frequente em diversos estudos. 1,3,11,20,21,22,28 De modo análogo, também pode ser considerada a variável cor da pele, uma vez que as crianças classificadas como pretas e/ou pardas provavelmente foram aquelas provenientes de famílias com maiores privações econômicas e sociais. $18,20,22$

No que se refere à idade da criança, observa-se que o risco de adquirir novas lesões de cárie se eleva com o aumento da idade, desde quando a criança estará progressivamente mais exposta a outros fatores determinantes, além do progressivo aparecimento de unidades dentárias na cavidade bucal.2,18 Observou-se ainda no presente estudo, que as práticas de aleitamento natural e artificial, se prolongaram além dos 12 e 24 meses, respectivamente, assim como o aleitamento durante o sono. Tal comportamento, aliado à ausência de adequada higiene oral e dieta cariogênica, foram considerados importantes preditores para a ocorrência de cárie, conforme descrito em outros estudos. 1,10,11,19,21,27

Constata-se que as condições de saúde bucal observadas no início do acompanhamento, como a presença de placa bacteriana, e a experiência anterior de cárie, inclusive em seus estágios iniciais (MBA), constituíram-se nos principais preditores para a ocorrência de novas lesões, o que está de acordo com outros estudos. ${ }^{20,28}$ Contudo, quando se considera o grupo de crianças livres de cárie no início do estudo, são os fatores socioeconômicos e demográficos aqueles que mais contribuem para a ocorrência da doença. ${ }^{18,20,22}$

Tendo em vista as características da população estudada, e na perspectiva de conformação de um modelo preditivo para a doença cárie, as variáveis que representavam a condição socioeconômica, seriam as principais responsáveis pela ocorrência do evento, até mesmo porque, seguindo uma cadeia etiológica, elas estariam influenciando os outros níveis de causalidade, que compreendem os aspectos ambientais, relativos à esfera do comportamento ou do estilo de vida, como os hábitos de aleitamento, 8,19,24,27 dieta/alto consumo de alimentos e bebidas açucaradas2,19,20,21 e hábitos de higiene oral/ consumo de flúor10,24 além dos aspectos biológicos individuais (peso, anemia, consumo medicamentos). $3,18,21$

A melhoria da situação de saúde bucal, mesmo para o grupo de crianças da mais tenra idade, implicaria em transformações sociais que promovessem impacto nas condições de vida existentes, repercutindo, de forma positiva, nas suas várias vertentes: trabalho, moradia, educação, renda, acesso a serviços de saúde.10,11,13 Por outro lado, ações específicas de promoção de saúde bucal podem e devem ser implantadas elou implementadas, no plano micro-estrutural, seja no âmbito dos serviços de saúde, seja no próprio ambiente da creche. 12 Ações de educação em saúde para educadores das creches com o potencial de replicá-las aos pais e responsáveis, ampliar o acesso aos serviços de saúde promovendo ações de diagnóstico e tratamento segundo risco de cárie e ações de prevenção com visitas periódicas na Atenção Básica devem ser reforçadas à esta faixa etária. Isto porque a criança menor de três anos constitui um grupo de difícil abordagem, especialmente quando há a necessidade de terapia restauradora. 7,8

As limitações do estudo incluem o tamanho da população estudada, que pode ter influenciado os resultados, visto que os cerca de $13 \%$ dos indivíduos que não participaram do seguimento poderiam apresentar condições de saúde bucal diferentes da população analisada, o que não foi possível averiguar. 
Também, o poder do estudo pode ter sido insuficiente para detectar associações positivas entre determinadas variáveis e a incidência de cárie. Além disso, o próprio instrumento de coleta, apesar de ter sido pré-testado no estudo piloto, apresentou dificuldades de interpretação pela população de estudo, o que pode ter comprometido a qualidade da informação obtida, a exemplo do tipo de aleitamento e respectiva duração. Há que se considerar ainda o viés de memória, uma vez que algumas informações eram referentes a comportamentos e situações vivenciadas no passado. Vale ressaltar ainda que na análise multivariada por tipo de creche, foram consideradas as creches filantrópicas e públicas. Entretanto, o perfil socioeconômico das crianças de ambas as creches era semelhante, uma vez que moravam na mesma área geográfica e apresentavam o mesmo modo de vida, recorrendo à alternativa da

\section{Referências}

1. Melo MMDC, Souza WV, Lima, MLC, Braga C. Fatores associados à cárie dentária em pré-escolares do Recife, Pernambuco, Brasil. Cad Saúde Pública. 2011; 27 (3): 47185.

2. Nunes AM, Silva AA, Alves CM, Hugo FN, Ribeiro CC. Factors underlying the polarization of early childhood caries within a high-risk population. BMC Public Health. 2014; 14: 988.

3. Dos Santos Junior VE, Sousa RM, Oliveira MC, Caldas Junior AF, Rosenblatt A. Early childhood caries and its relationship with perinatal, socioeconomic and nutritional risks: a cross-sectional study. BMC Oral Health. 2014; 14 : 47.

4. Narvai PC. Está ocorrendo um declínio de cárie no Brasil? Jornal da ABOPREV1996; 7-12.

5. Brasil. Ministério da Saúde. Secretaria de Atenção à Saúde. Departamento de Atenção Básica. Coordenação Nacional de Saúde Bucal. SB Brasil 2010. Pesquisa Nacional de Saúde Bucal. Resultados Principais. Brasília, DF; 2011.

6. Brasil. Ministério da Saúde. Secretaria de Atenção à Saúde. Departamento de Atenção Básica. Coordenação Nacional de Saúde Bucal. Condições de Saúde Bucal da População Brasileira 2002-2003. Resultados Principais. Brasília, DF; 2004.

7. Grindefjord M, Dahllof G, Nilsson B, Modéer T. Stepwise Prediction of Dental Caries in children up to 3,5 years of age. Caries Res. 1996; 30 (1): 256-66.

8. Harrison R, Wong T, Ewan C, Contreras B, Phung Y. Feeding practices and dental caries in an urban Canadian population of Vietnamese preschool children. J Dent Child.1997; 64: 112-7.

9. Wendt LK, Hallonsten AL, Koch G. Oral health in preschool children living in Sweden. Parte III - A longitudinal study. Risk analysis based on caries prevalence at creche filantrópica, muitas vezes, por não encontrar vaga na creche pública.

Um outro elemento a ser aprofundado em futuros estudos seria o uso da unidade de análise superfície dentária acometida pela doença, e não dente, como foi opção inicial neste trabalho. Talvez o primeiro permitisse maior acurácia por se tratar de um estudo de incidência com período não tão longo de seguimento.

Ressalta-se, todavia, que na área da saúde bucal, são escassos os estudos longitudinais, especialmente sobre a incidência de cárie em crianças pré-escolares. Desse modo, a presente coorte permitiu identificara vulnerabilidade social e econômica como fortes fatores de risco, utilizando taxas de incidência e de densidade de incidência de cárie precoce, o que possibilitou produzir evidências para o enfrentamento do problema nesta população.

three years of old and immigrant status. Swed Dent J. 1999; 23 (1): 17-25.

10. Olatosi OO, Inem V, Sofola OO, Prakash P, Sote EO. The prevalence of early childhood caries and its associated risk factors among preschool children referred to a tertiary care institution. Niger J Clin Pract. 2015; 18 (4): 493-501.

11. Stephen A, Krishnan R, Ramesh M, Kumar VS. Prevalence of early childhood caries and its risk factors in 18-72 month old children in Salem, Tamil Nadu. J Int Soc Prev Community Dent. 2015; 5(2): 95-102.

12. Morita MC, Morishima T, Yamazaki T, Chiba S. Prévalence de la carie dentaire chez des enfants Brésiliens de 0 à 36 mois. J d'Odonto-Stomatol Pédiatric. 1993; 3 (1): 19-28.

13. Tomita NE, Bijella VT, Lopes ES, Franco LJ. Prevalência de cárie dentária em crianças da faixa etária de 0 a 6 anos matriculadas em creches: importância de fatores socioeconômicos. Rev Saúde Pública. 1996; 30 (5): 413-20.

14. Carvalho JC, Figueiredo MJ, Vieira EO, Mestrinho HD. Caries Trends in Brazilian Non- Privileged preschool children en 1996 and 2006. Caries Res. 2009; 43 (1): 1-6.

15. Mattos-Graner RO, Rontani RM, Gavião MB, Bocatto HA. Prevalence in 6-36-th old Brazilian children. City Dent Health. 1996; 13 (2): 96-8.

16. Bonecker MJS, Guedes- Pinto AC, Walter LRF. Prevalência, distribuição e grau de afecção de cárie dentária em crianças de 0 a 36 meses de idade. Rev Assoc Paul Cir Dent. 1997; 51 (6): 535-9.

17. Barros SG, Castro-Alves A, Pugliese LS, Reis SRA. Contribuição ao estudo da cárie dentária em crianças de 030 meses. Pesq Odont Bras. 2001; 15 (3): 215-22.

18. Tang RS; Huang MC; Huang ST. Relationship between dental caries status and anemia in children with severe early childhood caries. Kaohsiung J Med Sci. 2013; 29 (6): 3306. 
19. Nakayama Y, Mori M. Association between nocturnal breastfeeding and snacking habits and the risk of early childhood caries in 18- to 23-month-old Japanese children. J Epidemiol. 2015; 25 (2): 142-7.

20. Warren JJ, Weber-Gasparoni K, Marshall TA, Drake DR, Dehkordi-Vakil F, Kolker JL, Dawson DV. Factors associated with dental caries experience in 1-year-old children. J Public Health Dent. 2008; 68 (2): 70-5.

21. Majorana A, Cagetti MG, Bardellini E, Amadori F, Conti G, Strohmenger L, Campus G. Feeding and smoking habits as cumulative risk factors for early childhood caries in toddlers, after adjustment for several behavioral determinants: a retrospective study. BMC Pediatr. 2014; 14: 45.

22. Moimaz SAS, Fadel CB, Lolli LF, Garbin CAS, Garbin AJI, Saliba NA. Social aspects of dental caries in the context of mother-child pairs. J Appl Oral Sci. 2014; 22 (1): 73-8.

23. Peres MA, Latorre MRDO, Sheiham A, Peres KG, Barros FC, Hernandez PG, Maas AMN, Romano AR, Victora CG. Determinantes sociais e biológicos da cárie dentária em crianças de 6 anos de idade: um estudo transversal aninhado numa coorte de nascidos vivos no Sul do Brasil. Rev Bras Epidemiol. 2003; 6 (4): 293- 306..

24. Leong PM, Gussy MG, Barrow SY, Silva-Sanigorski A, Waters E. A systematic review of risk factors during first year of life for early childhood caries. Int J Paediatr Dent 2013; 23 (4): 235-50.

Recebido em 6 de novembro de 2015

Versão final apresentada em 29 de dezembro de 2015

Aprovado em 5 de janeiro de 2016
25. Do LG, Scott JA, Thomson WM, Stamm JW, Rugg-Gunn AJ, Levy SM, Wong C, Devenish G, Ha DH, Spencer AJ. Common risk factor approach to address socioeconomic inequality in the oral health of preschool children-a prospective cohort study. BMC Public Health. 2014; 14: 429.

26. Breilh J. Epidemiologia. Economia, Política e Saúde. São Paulo: Editora UNESP/HUCITEC; 1991.p. 189-99.

27. Kato T, Yorifuji T, Yamakawa M, Inoue S, Saito K, Doi H, Kawachi I. Association of breast feeding with early childhood dental caries: Japanese population-based study. BMJ Open. 2015; 5(3): e006982.

28. Congiu G, Campus G, Lugliè PF. Early Childhood Caries (ECC) Prevalence and Background Factors: a review. Oral Health Prev Dent. 2014; 12 (1): 71-6.

29. Reisine S, Douglas JM. Psychosocial and behavioral issues in early chilhood caries. Comm Dent Oral Epidemiol. 1998; 26: $32-44$. 